\title{
Change of behaviour when selecting food products in a supermarket environment after reminding consumers about weight management
}

\author{
Anna-Maria Saarela* \\ Faculty of Business, Tourism and Culture, Savonia University of Applied Sciences, Microkatu 1S, \\ FI-70201 Kuopio, Finland
}

Submitted 10 July 2012: Final revision received 25 November 2012: Accepted 22 January 2013: First published online 27 February 2013

\begin{abstract}
Objective: The aim was to explore how the behaviour of consumers changed while they selected food in a supermarket environment after they were reminded about weight management. This investigation was carried out from the perspective of selection criteria, reading of package labels, nutritional quality of the products selected and time taken to select a product.

Design: The subjects, who were actively watching their weight, participated in two consecutive tasks in a supermarket. They were given a shopping list of eleven food categories and asked to think aloud while selecting from each category a product they usually buy and a product they would use for weight management. The data ( $n 792$ selections) were collected through interviews and a verbal analysis protocol combined with wireless audio-visual observation.

Subjects: Thirty-six consumers were recruited from a sample of 367 supermarket customers.

Setting: Kuopio, Finland.

Results: The subjects' behaviour changed radically after they were reminded about weight management. In the first selection, taste and familiarity were the main food selection criteria while in the latter selection the energy/fat content predominated. Consequently, the nutritional quality of products improved greatly because subjects read package labels twice as much in the latter selection. The time taken to select a product increased significantly, on average, from 23 (SD 10) to $60($ SD 51$) \mathrm{s} /$ product $(P=0 \cdot 000)$.

Conclusions: Only by reminding consumers about weight management was there a significant impact on their food selection behaviour. Marketing communication should be developed which quickly and easily promotes consumers' awareness of healthy food in supermarkets.
\end{abstract}

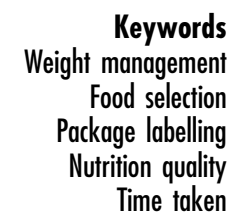

Consumers' choice of food is affected by their personal weight management ${ }^{(1)}$. Food selection at a supermarket is determined by several simultaneous needs ${ }^{(2,3)}$. The key factors influencing food choice are biological needs, such as hunger, appetite and taste; economic aspects, such as the cost of a product and the income of a consumer; practical skills relating to food preparation; social aspects, such as culture, family and meal patterns; psychological aspects, such as mood, stress and guilt; and other important aspects, such as attitudes, beliefs and knowledge ${ }^{(3-5)}$.

The relationship between the choice of food by consumers and their lifestyles is a complicated phenomenon $^{(3,6)}$. Generally, familiarity with a product, habit or sensory factors especially taste, price and healthiness are found to be important food selection factors ${ }^{(7-12)}$. According to studies conducted in real-life environments, when selecting food, consumers face several challenges from their own internal cues, as well as external cues such as understanding nutritional information or the nutritional content of a product under pressure of time ${ }^{(8,9,13-15)}$.

Also, there are several factors which interfere with consumers' weight management in a real food selection environment. For example, within certain product categories, there are several non-standardized ways of displaying products' nutritional information and the total energy and nutrient contents of different types of food products vary enormously ${ }^{(15-17)}$. In order to select low-energy foods, consumers have to read more package labels when identifying and separating them from those with a higher energy content ${ }^{(15)}$. Information overload may intentionally or unintentionally complicate healthy food selection from a weight management perspective at a supermarket ${ }^{(15,16,18-20)}$ and leads to the situation where only a few consumers who have active weight management goals read the 
package labels ${ }^{(8,9,21)}$. Rawson et $a l^{(22)}$ and Van Herpen and Van Trijp ${ }^{(20)}$ also stated in their studies that consumers only pay attention to labels when there are some motivating factors behind their food choice, such as dietary needs. Likewise, consumers who are actively trying to eat healthily pay more attention to nutritional labels than consumers for whom this is not the case ${ }^{(23)}$.

It is also generally known that in routine selection a consumer chooses the same product within a few seconds ${ }^{(3,9,24)}$. This means that information that is available, such as package labels, their evaluation and subsequent steps are neglected. However, according to the study by Grunert et al. ${ }^{(9)}$ consumers spent on average 29 s selecting food, so not all groceries were selected routinely.

There are several health disadvantages caused by risky behaviours, such as obesity through overeating. A change in consumer behaviour can be caused by a wide range of influences stemming from public health activities focused on the individual, community and environment ${ }^{(25,26)}$. The key question in health behaviour research is to understand and assess human nature in real-life environments ${ }^{(26-28)}$

Consequently, in the present study we sought to explore in real-life environments how consumers change their behaviour after reminding them about weight management while selecting food in a real supermarket environment, from the perspective of: (i) the selection criteria; (ii) the reading of package labels; (iii) the nutritional quality of products selected; and (iv) the time taken to select a product. The study also highlights betweenproduct variations in food selection criteria as well as variations in the time taken to select a product.

\section{Methods}

\section{Study subjects}

Approval from the Research Ethics Committee of the University Hospital of Kuopio (114/2009) was obtained prior to data collection. The study subjects ( $n$ 36) were recruited from a sample of 367 supermarket shoppers who answered a weight management survey in a supermarket in November-December 2009 in Kuopio, Finland. The subjects were intended to represent adult consumers with varied demographic backgrounds, corresponding to the profile of our survey responses (Table 1). The recruited subjects were slightly younger and better educated than the study sample from which they were derived. The subjects had good motivation to manage their weight especially in attempting to lose weight and making an effort to keep weight stable. Additionally, every third subject had CHD. Every fifth subject had lost weight during one year (mean $12.6 \mathrm{~kg}$, sD $5 \cdot 1 \mathrm{~kg}$ ). For every second subject, it had been suggested by a health care authority to lose weight. Every second subject answered that weight management generally plays a big role in his/her life.

\section{Field study in a supermarket}

The participation of all subjects was arranged by telephone in January-February 2010. A field experiment was carried out in April-May 2010 at a $3000 \mathrm{~m}^{2}$ supermarket with a range of about 12000 food products located in Finland, Kuopio; this also was the place for the first phase recruitment, i.e. where the survey was administered.

The subjects participated in two shopping rounds (see the following paragraphs). The verbalizations of the subjects while purchasing the foods were collected using a verbal analysis protocol, also known as the think-aloud method'. The eleven items on the shopping list (see Tables $2-4$ in Results section) were selected based on Finnish eating habits, representing typical energy and fat sources in the Finnish diet.

In the first round, the subjects were asked to select the products they usually buy. This was called the 'typical selection'. At the beginning of the experiment, to help the subjects to recall their memory about the products they habitually buy, the subjects were supported by asking them several questions, such as 'Please describe your typical shopping list, what it includes? What products do you buy every time? In which case do special offers matter?'

In the second round, called the 'weight management selection', the subjects were forced to think about more about healthy choices. At the beginning of the weight management selection, the subjects were instructed to 'Choose products that you have used when trying to manage your weight or that you think would be suitable for managing your weight'. No instructions were given even if any subject asked for help.

After the second shopping round, the subjects were interviewed on: (i) any difficulties encountered in selecting healthier food; (ii) background information and general health; and (iii) current weight management status. The participants were also given an opportunity to ask questions and they were given the selected products in thanks for their participation in the study, although they did not know in advance that this would happen. Also, data on nutritional content of the products selected ( $n$ 792) were observed from each food package. The shopping experiment, methods and technology used are reported in more detail elsewhere (A-M Saarela, T Kantanen, A Lapveteläinen et al., unpublished results).

\section{Data collection and analysis}

The study produced both quantitative and qualitative data about the subjects' food selection. Audio-visual and manual observation techniques were used to obtain both qualitative and quantitative data about: (i) what food selection criteria were mentioned when the subjects were during thinking aloud; (ii) how the subjects were noticing the package labels; (iii) which products the subjects selected from the nutritional perspective; and (iv) how long the subjects took to select a product. 
Table 1 Socio-economic characteristics of consumers enrolled in the present study $(n 36)$ as compared with the target population from the original survey $(n 367)$

\begin{tabular}{|c|c|c|c|}
\hline \multirow[b]{2}{*}{ Variable* $^{\star}$} & \multicolumn{2}{|c|}{ Present study } & \multirow{2}{*}{$\frac{\text { Original survey }}{\%}$} \\
\hline & $n$ & $\%$ & \\
\hline \multicolumn{4}{|l|}{ Gender } \\
\hline Male & 14 & 39 & 35 \\
\hline Female & 22 & 61 & 65 \\
\hline \multicolumn{4}{|l|}{ Age (years) } \\
\hline$<30$ & 4 & 11 & 11 \\
\hline $30-60$ & 27 & 75 & 59 \\
\hline$>60$ & 5 & 14 & 30 \\
\hline \multicolumn{4}{|l|}{ Marital status } \\
\hline Families with children & 18 & 50 & 29 \\
\hline Single & 4 & 11 & 16 \\
\hline Married or cohabiting & 11 & 31 & 47 \\
\hline Several adults cohabiting & 3 & 8 & 7 \\
\hline \multicolumn{4}{|l|}{ Level of highest education } \\
\hline Primary or lower secondary school & 1 & 3 & 18 \\
\hline Vocational school or equivalent & 17 & 47 & 60 \\
\hline University degree & 18 & 50 & 22 \\
\hline \multicolumn{4}{|l|}{ Employment status } \\
\hline Employed, high status & 4 & 11 & 11 \\
\hline Employee, entrepreneur, student & 25 & 69 & 78 \\
\hline Staying home, retired, unemployed & 7 & 20 & 11 \\
\hline \multicolumn{4}{|l|}{ BMI $\left(\mathrm{kg} / \mathrm{m}^{2}\right)$} \\
\hline$<25$ & 11 & 31 & 34 \\
\hline $25-30$ & 21 & 58 & 52 \\
\hline$>30$ & 4 & 11 & 14 \\
\hline \multicolumn{4}{|l|}{ Frequency of weight-loss trials during lifetime } \\
\hline No weight-loss trial or trying to keep weight stable & 9 & 25 & 35 \\
\hline Once or twice in lifetime & 9 & 25 & 24 \\
\hline Three or more times or constantly dieting & 18 & 50 & 31 \\
\hline \multicolumn{4}{|l|}{ Satisfied with own weight } \\
\hline Yes & 13 & 31 & 33 \\
\hline No, hopes to lose weight & 23 & 69 & 67 \\
\hline \multicolumn{4}{|l|}{ Aiming at losing weightt } \\
\hline Yes & 21 & 58 & 46 \\
\hline No & 15 & 42 & 53 \\
\hline \multicolumn{4}{|l|}{ Effort spent keeping weight stableł } \\
\hline Not at all or a little (score 1 to 5 ) & 0 & 0 & 16 \\
\hline Moderately (score 6 to 7 ) & 10 & 28 & 26 \\
\hline A great deal (score 8 to 10 ) & 26 & 72 & 58 \\
\hline
\end{tabular}

*Data were collected during a survey on weight management carried out in November and December 2009 at a Finnish supermarket ( $n$ 367). tAccording to the subjects' interviews in April and May 2010, the frequencies were: yes, 32/36; no, 4/36.

‡Willingness to make an effort to maintain a stable weight or slim down to a target weight, on a 10-point scale ( $1=$ 'not at all', $10=$ 'very much').

Three individuals were responsible for data collection during the two months of the field experiment: a research coordinator who was responsible for implementing the think-aloud method, a technician who was responsible for wireless audio-visual observation and a trained assistant who was responsible for manual observation and collecting product information. The light, inconspicuous and wireless camera on the subject's head recorded all the actions, movements and verbalizations of his/her selections. Overall, 396 selections were made on the first shopping round as each of thirty-six subjects had to choose eleven items and the same amount was done in the second round, for a total of 792 food choices.

Qualitative data on the subjects' verbalizations were collected while the subjects were acquiring their typical selections ( $n$ 396) and transcribed verbatim according to qualitative research guidelines ${ }^{(29)}$. The transcribed text was divided and coded using themes relevant to the study, such as (i) the selection criteria mentioned for each product category. Content analysis was performed using the data categorization tools incorporated into Microsoft ${ }^{\circledR}$ Word 2007.

The quantitative data were processed using the statistical software package IBM SPSS Version $17 \cdot 0$ for Windows. Summary statistics were calculated mainly in the case of analysing: (ii) the reading of package labels on the audiovisual tapes; (iii) the nutritional data collected about the food products selected (see the next paragraph); and (iv) the time taken to select a food product (see the paragraph after next). Correlations (Pearson's or Spearman's) were calculated in accordance with the scale and function of the variables examined in the study, as specified in the quantitative research guidelines.

All available information on the products was collected, such as the complete name, brand, manufacturer, package size, package labels, and the contents of energy, fat, 
Table 2 Three most common food selection criteria from all verbalizations during the product selections $(n$ 792) by the subjects $(n$ 36)

\begin{tabular}{|c|c|c|c|}
\hline \multirow[b]{2}{*}{ Product } & \multicolumn{3}{|c|}{ Typical selection } \\
\hline & \multicolumn{3}{|c|}{ Three most common food selection criteria of the subjects ( $n 36$ ) } \\
\hline Fat spread & Familiarity & Taste & Manufacturer \\
\hline Yoghurt & Taste & Fat & Package size \\
\hline Cold cuts & Taste & Ingredient & Sensory factors \\
\hline Ready meal & Taste & Familiarity & Ingredients \\
\hline Prepared salad & Ingredients & Familiarity & Taste \\
\hline Cheese & Taste & Price & Fat \\
\hline Bread & Ingredients & Taste & Familiarity \\
\hline Biscuit & Taste & Familiarity & Price \\
\hline Salad dressing & Taste & Familiarity & Familiarity \\
\hline Soft drink & Taste & Familiarity & Price \\
\hline Juice & Ingredients & Taste & Price \\
\hline \multirow[t]{2}{*}{ Total $(n 396)$} & Taste & Familiarity & Ingredients \\
\hline & \multicolumn{3}{|c|}{ Weight management selection } \\
\hline Product & \multicolumn{3}{|c|}{ Three most common food selection criteria of the subjects ( $n 36$ ) } \\
\hline Fat spread & Energy & Fat & Taste \\
\hline Yoghurt & Energy & Fat & Taste \\
\hline Cold cuts & Fat & Energy & Ingredients \\
\hline Ready meal & Energy & Ingredients & Fat \\
\hline Prepared salad & Energy & Fat & Ingredients \\
\hline Cheese & Fat & Taste & Energy \\
\hline Bread & Ingredients & Fibre & Freshness \\
\hline Biscuit & Energy & Ingredient/Sugar & Taste \\
\hline Salad dressing & Energy & Fat & Taste \\
\hline Soft drink & Energy & Sugar & Price \\
\hline Juice & Energy & Ingredient/Sugar & No additives \\
\hline Total (n 396) & Energy & Fat & Ingredients \\
\hline
\end{tabular}

carbohydrates and sugar. The energy values of products selected $(\mathrm{kJ} / 100 \mathrm{~g})$ were used to make possible the equal comparison and calculations between the different products selected. Furthermore, the nutritional quality of ingredients and the nutrients were derived from both the quantitative and qualitative data to see the nutritional change in product selection. A discussion of the nutritional change made in relation to the energy quantity examined in these studies is presented elsewhere (A-M Saarela, A Lapveteläinen, H Mykkänen et al., unpublished results).

The time taken to select a food product was determined from the wireless audio-visual recordings. The timing started when a participant stopped walking, turned a corner or paused in front of a relevant product category. Some participants continued to think about their selection (i.e. to verbalize their thoughts) after picking up the product chosen but before placing it in the shopping cart; in such cases we stopped timing either when the participant picked up the product or when it was clear that the final decision had been made.

\section{Results}

\section{Food selection criteria of products}

According to the results of the think-aloud method during the typical selection, generally the taste of a product was the most commonly used selection criterion for food when summarizing all of the criteria described in Table 2.
Furthermore, the familiarity and ingredients of a product were also important factors in food selection. The fat content of a product was mentioned when selecting fat spread, yoghurts and cheeses. The price of a product mattered especially in the case of cheeses, biscuits, soft drinks and juices (Table 2).

In the weight management selection, the selection criteria for food changed, concentrating mostly on the energy content of a product (Table 2). Furthermore, the fat content of a product was also an important factor when selecting food. The taste of a product was especially mentioned when selecting cheeses, but also in the choice of fat spreads, yoghurts, biscuits and salad dressings. The price mattered only with soft drinks. Freshness and the fibre content played an important role in the choice of breads (Table 2).

\section{Looking at package labels}

In the typical selection, the subjects did not examine any of the labels on $60 \%$ of selected products. When choosing fat spread, ready meals or bread, the subjects examined the labels less frequently than when comparing other choices in the typical selection. Generally, the frontof-pack labels were examined one in ten times, mostly when selecting cold cuts, juices or soft drinks; they were least examined in the case of ready meals, bread and salad dressing. The nutritional information was read one in five times, mostly when selecting salad dressings, ready 
meals, prepared salads and biscuits. By contrast, the nutritional information on soft drinks, fat spread and cheese was hardly looked at.

In the weight management selection, the subjects did not examine any of the labels on $21 \%$ of selected products. Generally, the front-of-pack labels were examined on $15 \%$ of the products selected, mostly when selecting prepared salads and least often in the case of ready meals or soft drinks. The subjects examined the nutritional information on $57 \%$ of selected items in the weight management selection, mostly when selecting salad dressing, biscuits and cold cuts. The nutritional information least often read was that of prepared salads. Finally, the subjects having children at home tended to read package labels less than other subjects $(r=0.509$, $P=0 \cdot 002$ ).

\section{Nutritional changes in the products selected}

Table 3 shows the qualitative examination of the type of products the subjects chose in the typical and weight management selections from an ingredient or nutritional perspective. The nutritional change across every product category between the typical and weight management selection is easily seen when reading the product selection summarized in Table 3. For instance, with ready meals, the ingredients of the products changed mostly from red meat to chicken, fish or vegetable-rich portions and in the latter selection subjects selected more soups (Table 3).

The individual quantitative energy reductions (in $\mathrm{kJ} / 100 \mathrm{~g}$ ) of the subjects are described in more detail elsewhere (A-M Saarela, A Lapveteläinen, H Mykkänen et al., unpublished results). In that paper, for all subjects, the energy content of the weight management selection was lower than that of the typical selection. However, in some single product selections, energy content reduction was either difficult or not desired.

Interestingly, if a subject selected a product with a lower energy content, the package labels of the one selected were examined for longer than in the typical selection $(r=-0.522, P=0 \cdot 001)$. Similarly, in the weight management selection, there was an even stronger correlation $(r=-0 \cdot 629, P=0 \cdot 000)$.

According to the interviews at the end of the experiment, when asked about the factors that prevented them from selecting healthier food, one in three subjects said that the price or taste of a product mattered most. One in four subjects said that sensory factors, such as the texture, appearance and colour of the product, were more important than its energy content. Other factors mentioned were the layout of the products and the ability to find them (7/36 subjects) along with habits, routines, attitudes (7/36) and time pressure (6/36).

\section{Time taken to select products}

In the weight management selection, the time taken to select a product was generally three times longer than in the typical selection (Table 4). In the weight management selection, the selection times for salad dressings and ready meals were the longest measured, whereas the times to select yoghurts, cheeses and soft drinks were the shortest. Interestingly, in the weight management selection, selecting bread took the least time while selecting cookies or a juice took the most time (Table 4).

In the typical selection, only a few of the products chosen $(6 \%)$ were first considered for over $1 \mathrm{~min}$, while in the weight management selection this rose to over a third of products (39\%; Table 4). Conversely, in the latter selection, a minority of products were chosen directly, in a few seconds, without any consideration of alternatives ( $9 \%$ of products chosen). The time spent during the product selections did not correlate at all; for example, the subject's quick choice in the first selection did not indicate the speed of his/her choices in the second.

Interestingly, the more time spent in product selection was moderately correlated $(r=0.353, P=0.035)$ to a decrease in the total energy content of all eleven products where energy values were quoted in $\mathrm{kJ} / 100 \mathrm{~g}$. Also, the more time taken to select a product, the more the package labels were examined: in the typical selection $(r=0.739, P=0.001)$ and in the weight management selection $(r=0 \cdot 504, P=0 \cdot 002)$.

\section{Discussion}

\section{Food selection criteria of products}

It is not always easy to put weight management into action while selecting food in a supermarket. Keränen ${ }^{(14)}$ wrote that when a consumer is managing his/her weight, one of the most important issues is to understand what his/her situation is. According to background information, the majority of the subjects in the present study had difficulties with their health which may have affected their food selection behaviour. Interestingly, in the typical selection, the subjects appreciated the taste or other nonnutritional-related factors more than the energy content of products. Other internal cues, such as habitual selection of the most familiar product, or external cues, such as the price of a product, overshadowed their attention to nutritional information ${ }^{(23,24)}$. However, after the first shopping round, the subjects were reminded of their hidden goal, weight management. Consequently, the majority of subjects immediately started to consider energy content or other ingredients to be the key factors in food selection, as also observed by Visschers et al. $^{\text {(23) }}$.

Our study's findings regarding food choice criteria (Table 2) are consistent with reports from previous studies which emphasized the importance of familiarity with the product ${ }^{(7,30)}$ and especially the product's taste and price $^{(10,12)}$. Also, Grunert et al ${ }^{(8)}$ have similarly reported that the most important food selection criterion was taste ( $52 \%$ of answers), followed by 'this is what my family wants' 
Table 3 Qualitative examination of the nutritional change from the ingredient or nutrient perspective between both product selections by the subjects ( $n$ 36)

\begin{tabular}{|c|c|c|c|}
\hline Product & Typical selection ( $n$ 36) & Weight management selection ( $n 36$ ) & $\begin{array}{l}\text { Additional descriptions about the change between the } \\
\text { selections }\end{array}$ \\
\hline Fat spread & $\begin{array}{l}\text { Spread }>60 \% \text { fat }(18) \text {, spread }<60 \% \\
\text { fat (18) }\end{array}$ & $\begin{array}{l}\text { Spread }>60 \% \text { fat }(13) \text {, spread }<60 \% \\
\text { fat }(23)\end{array}$ & $\begin{array}{l}13 \text { chose the same product, } 9 \text { chose butter-based spread in } \\
T^{*} \text { and } 8 \text { chose butter-based spread in } W^{\dagger}\end{array}$ \\
\hline Yoghurt & Yoghurt $>1 \%$ fat $(30)$, yoghurt $<1 \%(6)$ & Yoghurt $>1 \%$ fat (23), yoghurt $<1 \%$ fat $(13)$ & 9 chose the same product \\
\hline Cold cuts & $\begin{array}{l}\text { Ham (23), chicken/turkey (8), beef (1), } \\
\text { mixed ingredients (4) }\end{array}$ & $\begin{array}{l}\text { Ham (13), chicken/turkey (20), beef (2), mixed } \\
\text { ingredients (1) }\end{array}$ & $\begin{array}{l}12 \text { chose fatty products, such as salami in } T^{*} \text {, but no one } \\
\text { chose fatty products in } W+\text {, the leanest thin cold cuts were } \\
\text { selected by } 9 \text { in } T^{*} \text { and by } 20 \text { in } W+\end{array}$ \\
\hline Ready meal & $\begin{array}{l}\text { Red meat dish (21), chicken dish (6), } \\
\text { fish dish (5), vegetarian dish (2), } \\
\text { mixed ingredients (2) }\end{array}$ & $\begin{array}{l}\text { Red meat dish (10), chicken dish (7), } \\
\text { fish dish (8), vegetarian dish (11) }\end{array}$ & 5 chose soup in $\mathrm{T}^{*}$ and 19 in $\mathrm{Wt}$ \\
\hline Prepared salad & $\begin{array}{l}\text { Mayonnaise-based salad (19), grated } \\
\text { beet crop salad (10), lunch salad (7) }\end{array}$ & $\begin{array}{l}\text { Mayonnaise-based salad (2), grated beet } \\
\text { crop salad (14), lunch salad (10) }\end{array}$ & $\begin{array}{l}20 \text { replaced with the lighter one in the same product category, } \\
2 \text { chose the same brand, } 8 \text { replaced with the lighter one in } \\
\text { the same brand, } 6 \text { chose a product with higher energy } \\
\text { content in } W+\end{array}$ \\
\hline Cheese & $\begin{array}{l}\text { Cheese }>17 \% \text { fat }(20) \text {, cheese } 10-17 \% \\
\text { fat (14), cheese }<10 \% \text { fat }(2)\end{array}$ & $\begin{array}{l}\text { Cheese }>17 \% \text { fat }(6) \text {, cheese } 10-17 \% \\
\text { fat }(10), \text { cheese }<10 \% \text { fat }(20)\end{array}$ & $\begin{array}{l}3 \text { chose the same product, } 8 \text { the same brand, with lower fat } \\
\text { content, the majority chose the brand with the lower fat } \\
\text { content }\end{array}$ \\
\hline Bread & Rye bread (23), other rich in fibre bread (13) & Rye bread (35), oat bread (1) & $\begin{array}{l}12 \text { chose the same bread, } 12 \text { replaced white bread with } \\
\text { dark bread, } 12 \text { replaced rye bread with another rye } \\
\text { bread rich in fibre }\end{array}$ \\
\hline Biscuit & $\begin{array}{l}\text { Selection spreads, plenty of chocolate } \\
\text { cookies (21) }\end{array}$ & $\begin{array}{l}\text { Flapjacks }(9) \text {, biscuits with no fillings }(6) \\
\text { chocolate }(7), \text { biscuits reduced fat }(7) \\
\text { snack biscuit (7) }\end{array}$ & All changed brand $(36)$ \\
\hline Salad dressing & Light dressings (18), normal dressings (18) & Light dressings (18), normal dressings (18) & No one chose the same product, the garlic taste was favourite \\
\hline Soft drink & $\begin{array}{l}\text { Colas (13), light versions of cola } 8 / 13 \text {, } \\
\text { orange soft drink (12), light versions of } \\
\text { orange soft drink } 6 / 12 \text {, mixed (11) }\end{array}$ & $\begin{array}{l}\text { Colas (17), light versions of colas 16/17, } \\
\text { orange light soft drinks (11), } \\
\text { other options (8) }\end{array}$ & $\begin{array}{l}14 \text { chose the same drink, } 17 \text { replaced to lighter one with the } \\
\text { same brand, } 3 \text { did not replace the drink for a lighter one, } \\
2 \text { changed flavour of a product }\end{array}$ \\
\hline Juice & $\begin{array}{l}\text { Orange juices (7), exotic fruit juices (19), } \\
\text { berry juice (7), apple juices (3) }\end{array}$ & $\begin{array}{l}\text { A range was selected, the most common } \\
\text { choice was orange juice (11) }\end{array}$ & $\begin{array}{l}8 \text { chose the same juice, } 29 \text { replaced it with the lighter one, } \\
1 \text { did not replace the drink with a lighter one }\end{array}$ \\
\hline
\end{tabular}

${ }^{*} T=$ Typical selection.

$T=$ Weight management selection.
$+W=$. 
Table 4 Average time taken in seconds by the study subjects ( $n$ 36) to select a product from eleven product categories in typical and weight management selections

\begin{tabular}{|c|c|c|c|c|c|}
\hline \multirow[b]{2}{*}{ Product } & \multicolumn{2}{|c|}{$\begin{array}{l}\text { Typical } \\
\text { selection* }\end{array}$} & \multicolumn{3}{|c|}{$\begin{array}{c}\text { Weight management } \\
\text { selectiont }\end{array}$} \\
\hline & Mean & SD & Mean & SD & Rank orderł \\
\hline Fat spread & $6 \cdot 8$ & $6 \cdot 8$ & $63 \cdot 7$ & $62 \cdot 1$ & 7 \\
\hline Yoghurt & $12 \cdot 7$ & $11 \cdot 9$ & $42 \cdot 3$ & $44 \cdot 2$ & 2 \\
\hline Cheese & $15 \cdot 1$ & $13 \cdot 1$ & $42 \cdot 5$ & $43 \cdot 6$ & 3 \\
\hline Soft drink & $20 \cdot 9$ & $16 \cdot 4$ & $43 \cdot 4$ & $40 \cdot 7$ & 4 \\
\hline Cookies & $21 \cdot 9$ & $14 \cdot 6$ & $88 \cdot 2$ & $63 \cdot 6$ & 11 \\
\hline Cold cuts & $23 \cdot 9$ & $16 \cdot 1$ & $56 \cdot 1$ & $43 \cdot 7$ & 5 \\
\hline Juice & $27 \cdot 7$ & $27 \cdot 7$ & $77 \cdot 0$ & $57 \cdot 1$ & 10 \\
\hline Bread & $27 \cdot 9$ & $22 \cdot 6$ & $40 \cdot 9$ & $32 \cdot 8$ & 1 \\
\hline Ready meal & $28 \cdot 8$ & $26 \cdot 4$ & $73 \cdot 1$ & $45 \cdot 4$ & 8 \\
\hline Prepared salad & $30 \cdot 3$ & $40 \cdot 0$ & $61 \cdot 5$ & $45 \cdot 0$ & 6 \\
\hline Salad dressing & $33 \cdot 1$ & $38 \cdot 1$ & $74 \cdot 8$ & $54 \cdot 2$ & 9 \\
\hline All (n 396) & $22 \cdot 6 \S$ & $10 \cdot 4$ & $60 \cdot 3 \S$ & $51 \cdot 2$ & - \\
\hline
\end{tabular}

*The sum of individual differences of time taken varied from 99 to $519 \mathrm{~s}$ per eleven products.

†The sum of individual differences of time taken varied from 236 to $1407 \mathrm{~s}$ per eleven products.

$\ddagger$ Time taken (s) in order from the smallest (1) to the biggest value (11)

$\S$ Statistically significant difference $(P=0 \cdot 000)$.

(13\%), price or special offer (11\%) and health and nutrition (8\%). This has been reported in other papers ${ }^{(7,10-12)}$.

However, the present study has provided the most detailed description to date of the changes in food selection criteria of eleven product categories, including the three most commonly attributed criteria (Table 2). This product-specific information about the behaviour of consumers towards nutrition is valuable to food developers and marketers, especially Finnish food manufacturers, when they are developing targeted marketing messages.

\section{Reading package labels}

In the typical selection, the majority of consumers did not read the nutritional facts on packages, as also observed by Cowburn and Stockley ${ }^{(18)}$, Graham and Jeffery ${ }^{(21)}$, and Van Herpen and Van Trijp ${ }^{(20)}$. According to our findings, generally the taste and the price of a product mattered more in food selection than nutritional issues, as also reported by Visschers et al. ${ }^{(23)}$. Moreover, there seemed to be food packages with too many nutritional messages on, or with small or complex notes, for consumers to read and understand; this has been reported previously ${ }^{(15,18,19)}$.

Recently, Van Herpen and Van Trijp ${ }^{(20)}$ came to the same conclusion that generally very limited attention is paid to nutritional labels unless consumers are motivated enough by dietary issues. However, when these labels are read, the quality of consumers' diet may improve ${ }^{(31,32)}$. In fact, in the current study, when the subjects were deliberately reminded to think about weight management in the second round, the more a subject read the labels, the more the subject selected products with lower energy content. Interestingly, in the weight management selection, front-of-pack labels were read less than in the typical selection. The reason was that the subjects wanted to read the more precise nutritional information about the product on the other side of the package. So nutritional tables mattered more and gave more information to subjects than other labels; this was also observed by Van Herpen and Van Trijp ${ }^{(20)}$.

\section{Nutritional changes and time taken to select products}

As we noticed in this field experiment, many consumers managed to find new and desirable products for their everyday use. Above all, the majority of subjects were able to change their nutritional behaviour significantly, as well as improving the nutritional quality of the products they chose compared with the first product selection (Table 3). One significant explanation was that the subjects read nutritional labels more ${ }^{(28)}$. Campos et al. ${ }^{(31)}$ noted that there is a constant link between the use of nutritional labels and healthier diets. Motivating the subjects in the second selection about their weight management revealed their ability to select healthier products, as found by Rawson et al. ${ }^{(22)}$, Van Herpen and Van Trijp ${ }^{(20)}$ and Visschers et $a l^{(23)}$. The reduction in energy content made in terms of quality and quantity between the selections implied that the ability and willingness to make that reduction varied between the subjects (A-M Saarela, A Lapveteläinen, H Mykkänen et al., unpublished results).

Additionally, several subjects, many of whom looked after children at home, pointed out during the interviews that 'time is money'. As we observed, it took time to replace the familiar product with a healthier alternative. However, many consumers want to do their shopping quickly (A-M Saarela, T Kantanen, A Lapveteläinen et al., unpublished results). Consequently, there is only limited time available for the selection of low-energy products for many consumers, so innovative solutions are needed to make consumer food selection easier.

Finally, according to Table 4, the average time that we recorded for selecting a food product in the typical selection (23 s) is close to that reported previously: $29 \mathrm{~s}$ by Grunert et $a l .{ }^{(9)}$. However, no study has been made on the time taken to select a product by a consumer managing his/her weight. Furthermore, since current knowledge about the time that consumers spend selecting food products is limited, especially with respect to product categories $^{(9)}$, the present study highlighted differences in the time taken between product categories. It offers a valuable insight for better understanding consumers' nutritional behaviour in the real environments that Kingstone et al. $^{(27)}$ and Grunert and Wills ${ }^{(28)}$ recommended should be used for this type of research.

\section{Future innovations to belp consumers choose bealtbier food}

In supermarkets, there is still room for innovative consumer services. Personalized nutritional information is 
needed rather than complex package labels. Innovative technological solutions should be found and piloted with consumers by manufacturers working cooperatively with retailers in the areas relating to marketing psychology and communication of nutritional information ${ }^{(15,26)}$.

Shankar et al. ${ }^{(33)}$ described several innovative ways to create more dialogue between consumers and the products available, such as using digital technology. In fact, VTT Technical Research Centre of Finland has carried out a project called 'Hybridmedia as a tool to deliver personalized product-specific information about food'. The basic idea was a mobile phone application using wireless Internet, camera phones and food packages. The consumer was able to collect product information, irrespective of time and location ${ }^{(19)}$. However, in the final project report, it was stated that the technology should be further developed by using more audio-visual messages and increasing the interactiveness of the system.

Further consideration of previous discussions and of research by Colby et al. ${ }^{(13)}$, which pointed out that dietitians are able to increase consumers' awareness of package labelling, suggests an innovative solution: could dietitians in supermarkets be able to help consumers with the overall nutritional content of food items, as stated in the paper by Saarela et $a l^{(15)}$ ? Also, should we focus on behaviour change through innovations such as building cues into food products that indicate what consumers need to achieve healthiness, as Lundahl ${ }^{(26)}$ has stated? Could there be possibilities to include health promotion messages into online shopping services, as Järvinen ${ }^{(19)}$ has piloted?

\section{Conclusion}

Generally, consumers do not actively think about nutritional issues or read the nutritional facts on packages when habitually and routinely selecting food. When the dormant motivation of weight management is awoken by simply reminding consumers, it has a significant impact on their food selection behaviour. Consequently, an interesting and challenging question is how to awaken that motivation so that the consumer chooses healthy food alternatives in supermarkets.

Consumers should be helped by developing marketing communication that quickly promotes consumers' awareness of the healthy food choices in supermarket environments. The interesting questions are: (i) what it is the ability or the willingness of consumers to change their behaviour and (ii) how are different parties, such as food producers, marketers, retailers and other actors, able to support this change? After all, a grocery store is often the place where consumers change their mind about the products they are going to buy and where, ultimately, they buy them from. The most important question is: (iii) will we find consumer behaviour-driven innovations in the foreseeable future which encourage consumers to meet their weight management goals in a grocery store? This requires product developers to consider the entire consumer shopping experience in the social context. The improved nutritional quality of products benefits the welfare of both consumer and society alike, as well as improving society's economy in the long run by decreasing the costs of health care.

\section{Acknowledgements}

Sources of funding: The current study was part of a multidisciplinary project 'Consumers in the weight management market', 2009-2011, that analysed the daily choices and experiences of consumers with food products related to weight management and aimed to understand the factors which increase the motivation for a change in behaviour. The project was carried out in cooperation with six universities and research institutes in Finland and was funded by the Finnish Funding Agency for Technology and Innovation. Conflicts of interest: The author declares that she has no conflict of interest. Author's contribution: The author was in charge of the whole design and execution of the study and analysis. Acknowledgements: The author wishes to acknowledge Ms Tammela for recruiting the subjects for the study; Ms Meriläinen and Ms Perttula for their assistance with the data collection; Ms Rajapolvi for her assistance in transcriptions; the shopkeeper, Mr Kostilainen, who gave permission to collect the data at the supermarket; several pilot consumers, especially Ms Lapveteläinen and Mr Kantanen; and the weight management consumers for their participation. The author also thanks A. Lapveteläinen PhD for her leadership role, enduring enthusiasm and continuing guidance during the entire follow-up study.

\section{References}

1. Ello-Martin JA, Ledikwe JH \& Rolls BJ (2005) The influence of food portion size and energy density on energy intake: implications for weight management. Am J Clin Nutr 82, 1 Suppl., 236S-241S.

2. Frewer L, Risvik E \& Schifferstein H (2010) Food, People and Society. A European Perspective of Consumers' Food Choices. Berlin/Heidelberg: Springer-Verlag.

3. Shepherd R \& Raats M (2006) The Psychology of Food Choice. Wallingford: CABI Publishing.

4. Bellisle F (2003) Why should we study human food intake behaviour? Nutr Metab Cardiovasc Dis 13, 189-193.

5. MacFie H (2007) Consumer-led Food Product Development, 18th ed. Cambridge: Woodhead Publishing.

6. Pérez-Cueto FJA, Verbeke W, de Barcellos MD et al. (2010) Food-related lifestyles and their association to obesity in five European countries. Appetite 54, 156-162.

7. Contento IR, Williams SS, Michela JL et al. (2006) Understanding the food choice process of adolescents in the context of family and friends. J Adolesc Health 38, 575-582.

8. Grunert KG, Fernández-Celemín L \& Wills JM (2010) Use and understanding of nutrition information on food labels in six European countries. J Public Health 18, 261-277. 
9. Grunert KG, Wills JM \& Fernández-Celemín L (2010) Nutrition knowledge, and use and understanding of nutrition information on food labels among consumers in the UK. Appetite 55, 177-189.

10. Honkanen P \& Frewer L (2009) Russian consumers' motives for food choice. Appetite 52, 363-371.

11. Sloan AE (2012) What, when, and where America eats. Food Technol 66, 20-32.

12. Steenhuis IH, Waterlander WE \& de Mul A (2011) Consumer food choices: the role of price and pricing strategies. Public Health Nutr 14, 2220-2226.

13. Dijksterhuis A, Smith PK, Van Baaren RB et al. (2005) The unconscious consumer: effects of environment on consumer behavior. J Consum Psychol 15, 193-202.

14. Keränen A-M (2011) Lifestyle interventions in treatment of obese adults. Eating behaviour and other factors affecting weight loss and maintenance. Doctoral Dissertation, University of Oulu.

15. Saarela A-M, Keinänen A-R \& Rissanen R (2012) Energy profiles and nutrition information in food product categories selected in Finnish grocery stores, considered from a weight management perspective. J Res Consum $\mathbf{2 1}$, $1-17$.

16. Colby SE, Johnson L, Scheett A et al. (2010) Nutrition marketing on food labels. J Nutr Educ Behav 42, 92-98.

17. Drichoutis AC, Lazaridis P \& Nayga RM (2006) Consumer use of nutritional food labels. A review of research studies and issues. Acad Mark Sci Rev 9, 1-22.

18. Cowburn G \& Stockley L (2005) Consumer understanding and use of nutrition labelling: a systematic review. Public Health Nutr 8, 21-28.

19. Järvinen $\mathrm{T}$ (editor) (2005) Hybridmedia As a Tool to Deliver Personalised Product-specific Information About Food. Report of the TIVIK Project, p. 34. Espoo: VTT Information Technology; available at http://www.vtt.fi/inf/ pdf/tiedotteet/2005/T2304.pdf

20. Van Herpen E \& Van Trijp HCM (2011) Front-of-pack nutrition labels. Their effect on attention and choices when consumers have varying goals and time constraints. Appetite 57, 148-160.
21. Graham DJ \& Jeffery RW (2011) Location, location, location: eye-tracking evidence that consumers preferentially view prominently positioned nutrition information. J Am Diet Assoc 111, 1704-1711.

22. Rawson D, Janes I \& Jordan K (2008) Pilot Study to Investigate the Potential of Eye Tracking as a Technique for FSA Food Labelling Behaviour Research. Report for the FSA. London: Eyetracker UK; available at http://www.food.gov. uk/multimedia/pdfs/eyetracking.pdf

23. Visschers VHM, Hess R \& Siegrist M (2010) Health motivation and product design determine consumers' visual attention to nutrition information on food products. Public Health Nutr 13, 1099-1106.

24. Martin N (2012) Habit: $95 \%$ of Behavior Markets Ignore. Upper Saddle River, NJ: FT Press.

25. Armitage CJ, Sheeran P, Conner M et al. (2004) Stages of change or changes of stage? Predicting transitions in transtheoretical model stages in relation to healthy food choice. J Consult Clin Psychol 72, 491-509.

26. Lundahl DS (2012) Breakthrough Food Product Innovation Through Emotions Research. London: Elsevier Inc.

27. Kingstone A, Smilek D, Ritsic J et al. (2003) Attention researchers: it is time to take a look at the real world. Curr Dir Psychol Sci 12, 176-184.

28. Grunert KG \& Wills JM (2007) A review of European research on consumer response to nutrition information on food labels. J Public Health 15, 385-399.

29. Silverman D (2010) Doing Qualitative Research. London: SAGE Publications.

30. Marquis M \& Shatenstein B (2007) Food choice motives and the importance of family meals: among immigrant mothers. Can J Diet Pract Res 66, 77-82.

31. Campos S, Doxey J \& Hammond D (2011) Nutrition labels on pre-packaged foods: a systematic review. Public Health Nutr 14, 1496-1506.

32. Guthrie JF, Fox JJ, Cleveland LE et al. (1995) Who uses nutrition labeling, and what effect does label use have on diet quality? J Nutr Educ 27, 163-172.

33. Shankar V, Inman J, Mantrala M et al. (2011) Innovations in shopper marketing: current insights and future research issues. J Retail 87, 29-42. 